\title{
Tradycyjne funkcje czasopisma naukowego a współczesne technologie komunikacyjne
}

Streszczenie. Czasopismo naukowe stanowi od połowy XVII wieku najważniejsze medium komunikacji w społeczności uczonych. Spełnia ono również wiele innych funkcji, takich jak selekcja jakościowa, archiwizacja i przynoszenie uznania autorom. Konieczność istnienia czasopisma dla rozwoju nauki była kwestionowana, również z pozycji antropologii kulturowej. Część z jego funkcji można już obecnie zastąpić innymi rozwiązaniami, pojawiającymi się wraz z rozwojem technologii informacyjnych i komunikacyjnych. Różne propozycje stworzenia nowej formuły czasopisma nie zapewniają właściwego spełniania jego wszystkich dotychczasowych funkcji. Szczególnie ważna i ciekawa wydaje się możliwość spojrzenia na procedury nauki związane z publikowaniem w czasopismach jako na rytuał, który utrwala poczucie tożsamości i integrację części społeczności uczonych związanej z określonym obszarem badawczym i szkołą metodologiczną.

SŁowA KLuczowe: czasopisma naukowe, czasopisma elektroniczne, funkcje czasopism, zachowania rytualne $\mathrm{w}$ nauce.

Wraz z rozwojem i dostępnością komputerowych technologii informacyjno-komunikacyjnych w ostatnich kilku dekadach narastała również dyskusja nad możliwością zastąpienia dotychczasowych sposobów interakcji środowisk naukowych przez nowe media elektroniczne. Wbrew pozorom nie jest to dyskusja bez precedensu w historii. Kiedy za sprawą Jana Gutenberga i jego następców upowszechniła się w Europie technologia druku na papierze, wybitny humanista Jan Trithemius (1462-1516), opat klasztoru benedyktynów w Sponheim i twórca jego biblioteki, odnosił się z dużą rezerwą do nowego wynalazku. W swej pochwale sztuki rękopiśmiennej (De laude scriptorum manualium, 1492) podnosił (tak nadal istotną dla bibliotekarzy, szczególnie w kontekście problemów z „kwaśnym 
papierem”) kwestię długowieczności książek drukowanych: „Albowiem dzieło drukowane jest rzeczą z papieru (res papyrea), a zatem ulegnie całkowitemu rozkładowi w krótkim czasie; ale autor, który zawierza swoje pisma pergaminowi, przedłuża żywot zarówno swój, jak i swoich dzieł, na wiele lat $w$ przyszłośćc ${ }^{\prime 1}$. Z licznych innych argumentów dowodzących, że druk może służyć jedynie celom doraźnym i zapewne jest przejściową moda, szczególnie ciekawą analogię do obecnej dyskusji stanowi twierdzenie Trithemiusa, iż sama czynność pisania ręcznego, a także przepisywania dzieł innych autorów przynosi głębsze rozumienie rozważanych problemów, a w przypadku tekstów religijnych jest również rodzajem modlitwy i medytacji. Dzisiaj słyszymy częste głosy, zwłaszcza ze strony uczonych starszego pokolenia przemawiających z pozycji autorytetu, że komputery i Internet stanowią zagrożenie dla właściwego funkcjonowania nauki, pozwalają bowiem na łatwe kopiowanie i wklejanie fragmentów tekstu, bez należytego namysłu. Podobnie jednak jak czcigodnemu opatowi ze Sponheim nie udało się powstrzymać rozwoju nowej technologii mimo słusznych i racjonalnych argumentów, tak i współczesna rewolucja medialna z pewnością nie da się zatrzymać - jedyne, co można zrobić, to starać się ukierunkować jej nurt w taki sposób, aby dotychczasowe sposoby działania nauki i tworzenia wiedzy nie zostały zarzucone, ale udoskonalone.

Wielu współczesnym uczonym trudno sobie wyobrazić świat bez czasopism naukowych, choć przecież nie istnieją one od zawsze, a tylko niewiele ponad 350 lat. Co więcej, wiele wskazuje na to, że mogą wkrótce przestać istnieć, ze względów zarówno metodologicznych, jak i czysto ekonomicznych ${ }^{2}$. Można wręcz uznać je za zjawisko efemeryczne w historii nauki, niezależnie nawet od kiedy liczyć jej początki ${ }^{3}$. Zapewne jedną z przyczyn tak głębokiego utożsamienia czasopisma naukowego z samą nauką było pojawienie się go w połowie XVII wieku, w kulminacyjnym okresie kształtowania się nowożytnej metody naukowej i w ścisłym z nią powiązaniu. Obecny kryzys wydawnictw naukowych i pojawienie się zupełnie nowych możliwości pozwalają na praktyczne wdrażanie tego, co przewidywał (albo raczej - o czym marzył) Vanevar Bush w swym legendarnym już artykule z 1945 roku, dostrzegając już wówczas nieadekwat-

\footnotetext{
${ }^{1}$ Cyt. za: N.L. Brann, The Abbot Trithemius (1462-1516): the renaissance of monastic humanism, Leiden 1981 (Studies in the history of Christian thought, 24), s. 151.

${ }^{2}$ P. Nowak, "Samopublikowanie": stara metoda - nowy sens w dobie e-science, "Biblioteka" 13 (22), 2009, s. 88-89.

${ }^{3}$ D.C. Lindberg, The beginnings of western science: the European scientific tradition in philosophical, religious, and institutional context, prehistory to A.D. 1450, wyd. 2 zmien., Chicago 2007, s. 1-20.
} 
ność starych metod działania nauki, w tym również czasopism i systemu recenzowania wyników badań 4 . Nic zatem dziwnego, że od początku pojawienia się sieci komputerowych, a później Internetu, wielu entuzjastów widziało w tym możliwość realizacji wizji Busha. Jednak dopiero kiedy w 1992 roku Tim Berners-Lee stworzył sieć WWW i w krótkim czasie hipertekst stał się wręcz sposobem myślenia, również bardziej konserwatywni uczeni włączyli się do dyskusji nad istotą czasopism naukowych w nowej epoce i potrzebą ich utrzymywania w dotychczasowej formie. Jednym z ciekawszych głosów w tej dyskusji był artykuł Bruce’a Mortona, który już w tytule zadał intrygujące pytanie: „Czy czasopismo naukowe,

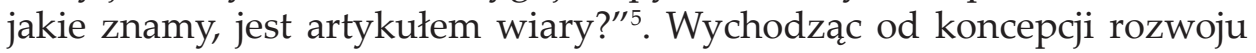
nauki Thomasa Kuhna, dowodził, że choć „paradygmat papierowy” był niezwykle przydatny, obecnie następuje nieunikniony zwrot (rewolucja) i rozpoczyna się "paradygmat postpapierowy”, a zatem trzeba naukę uwolnić z ograniczeń medium drukowanego. Nie był w tych poglądach odosobniony. Zarówno wcześniej, jak i później pojawiało się wiele czasopism naukowych ukazujących się wyłącznie w formie elektronicznej ${ }^{6}$, ale po czternastu latach sytuacja $\mathrm{w}$ głównym nurcie nauki nie zmieniła się radykalnie. Nadal stawiane jest pytanie: „Dlaczego wydawanie publikacji naukowych jeszcze nie uległo dezintegracji?"7, a choć najbardziej liczące się czasopisma stały się dziś powszechnie dostępne w wersji elektronicznej, najczęściej stanowią jedynie kopię edycji papierowej. Co najważniejsze jednak, sama koncepcja i forma czasopisma naukowego nie ewoluują istotnie, potwierdzając w pewnym sensie trafność sądu Mortona: środowiska naukowe wierza, że czasopismo stanowi nienaruszalny i konieczny element tworzenia wiedzy naukowej.

Wiara jest w swej istocie irracjonalna, ale przekonanie o racjonalności procedur nauki jest również w dużej mierze kwestią wiary, jak przekonująco dowodził Paul Feyerabend, twórca szkoły anarchizmu metodologicznego ${ }^{8}$. Głęboka wiara w słuszność i nienaruszalność stosowanych narzę-

${ }^{4}$ V. Bush, As We May Think, „The Atlantic Monthly" 1945, nr 176 [online], [dostęp: 20.02.2010], dostępny w Internecie: http://www.theatlantic.com/doc/194507/bush.

${ }^{5} \mathrm{~B}$. Morton, Is the Journal as We Know It an Article of Faith? An Open Letter to the Faculty, „,The Public-Access Computer Systems Review” 8, 1997, nr 2 [online], [dostęp: 20.02.2010], dostępny w Internecie: http://epress.lib.uh.edu/pr/v8/n2/mort8n2.html (wcześniej opublikowany w formie papierowej w „The Montana Professor” 7, 1997, s. 11-14).

${ }^{6}$ M. Nahotko, Naukowe czasopisma elektroniczne, Warszawa 2007.

${ }^{7}$ M. Clarke, Why Hasn't Scientific Publishing Been Disrupted Already?, „The Scholarly Kitchen" 2010[online], [dostęp:20.02.2010], dostępny w Internecie:http://scholarlykitchen.sspnet.org/2010/01/04/why-hasnt-scientific-publishing-been-disrupted-already.

${ }^{8}$ P. Feyerabend, Przeciw metodzie, przeł. S. Wiertlewski, Wrocław 1996. 
dzi i procedur naukowych prowadzi, podobnie jak przekonania religijne, magiczne czy artystyczne, do rytualizacji owych procedur i stosowania ich nawet wówczas, kiedy przestają być efektywne i stanowią raczej przeszkodę niż pomoc w dalszym i szybszym rozwoju nauki ${ }^{9}$. Niezwykle interesujące są w tym zakresie obserwacje Jamesa Wilce'a, który na podstawie analizy tworzenia i dystrybucji tekstów antropologicznych wysunął tezę o rytualnym charakterze takiej działalności ${ }^{10}$. Ponieważ rytualizacja następuje wówczas, gdy wykonywane czynności zatracają swój pierwotny cel i są powtarzane jako element tradycji, konstatacja taka wskazuje na wyczerpanie się funkcjonalności czasopisma naukowego. Inne formalne narzędzia generowania wiedzy istniały w nauce od czasów najdawniejszych, przechodziły przez fazę rytualizacji i w końcu zanikały. Wysoce sformalizowany schemat dysputy scholastycznej stanowił wielkie osiągnięcie średniowiecznej metodologii, ale w XVII i XVIII wieku był już jedynie rytuałem odtwarzanym na zacofanych uniwersytetach ${ }^{11}$.

Innym rytuałem nauki średniowiecznej, a szczególnie renesansowej, była wymiana informacji drogą listową. Epistolografia naukowa ma jeszcze starożytne korzenie, a jej największe nasilenie przypada na XVI i XVII wiek, kiedy to powstawały w Europie coraz bardziej sformalizowane sieci korespondencyjne, nazywane nawet "republikami korespondencyjnymi" (respublicae literariae). Stosowany do dziś w wielu towarzystwach naukowych tytuł „członek korespondent" ma również charakter rytualny, odwołujący się do tradycji z tamtego okresu, a obecnie zawierający jedynie treść symboliczną. Najbardziej aktywne z owych sieci miały swoich centralnych koordynatorów, zbierających nadsyłane do nich wiadomości i rozsyłających je do pozostałych uczestników. Jednym z takich najwcześniejszych "donosicieli", jak ich nazywano w Anglii (intelligencer), był Nicolas-Claude Fabri de Peiresc (1580-1637), a najważniejsi to Ismaël Boulliau (1605-1694) we Francji i Henry Oldenburg (ok. 1618-1677) w Anglii. Ten ostatni ma szczególne zasługi, nie tylko bowiem doprowadził do powstania Royal Society, pierwszego nowoczesnego towarzystwa naukowego, i przez wiele lat był jego sekretarzem, ale także zainicjował w 1655 roku wydawanie pierwszego czasopisma naukowego "Philosophical Transactions”, które

${ }^{9} \mathrm{Na}$ temat dwóch różnych podejść do rozumienia rytuału antropologicznego i filozoficznego zobacz odpowiednio: V.W. Turner, The ritual process. Structure and anti-structure, Chicago 1969 i L. Wittgenstein, Uwagi o "Złotej Gałęzi" Frazera, przeł. A. Orzechowski, Warszawa 1998.

${ }^{10}$ J.M. Wilce, Magical Laments and Anthropological Reflections: The Production and Circulation of Anthropological Text as Ritual Activity, "Current Anthropology" 47, 2006, nr 6, s. 891-914.

${ }^{11} \mathrm{Na}$ Uniwersytecie Harvarda jeszcze do początku XIX wieku. 
zastąpiło - dzięki technologii druku - wyczerpaną już wówczas formułę sieci korespondencyjnych. Do pierwszeństwa w tym względzie pretendują również Francuzi, których "Journal des sçavans” zaczął ukazywać się 5 stycznia 1665 roku, podczas gdy pierwszy numer periodyku angielskiego został wydany dopiero 6 marca tegoż roku; choć czasopismo francuskie nie było wyłącznie naukowe.

Ewolucja od listów prywatnych i listów otwartych, poprzez sieci korespondencyjne, do czasopisma naukowego wskazuje na podstawową funkcję, która stanowiła istotę tego ostatniego w momencie jego powstania, a mianowicie funkcję informacyjno-komunikacyjną. Henry Oldenburg również jako pierwszy wprowadził recenzowanie nadsyłanych materiałów przed ich publikacją co dzisiaj jest nieodłącznym elementem stanowiącym o naukowości periodyku ${ }^{12}$. Były to co prawda recenzje dokonywane $\mathrm{w}$ redakcji, a nie jeszcze peer-review (te pojawiły się w XVIII wieku), ale takie podejście jest również obecnie stosowane $\mathrm{w}$ wielu czasopismach, choć redakcje niechętnie się do tego przyznają. Z czasem pojawił się szereg dalszych funkcji czasopisma naukowego, a współcześni teoretycy proponują wiele ich typologii, w zależności od przyjmowanych kryteriów. Długą listę takich funkcji zestawił z różnych źródeł Piotr Nowak ${ }^{13}$, ale niewątpliwie można do niej dodać kolejne, gdyby przyjąć jeszcze inne punkty widzenia. Wśród cytowanych przez niego opinii znalazło się też twierdzenie Dereka J. de Solla Price'a, jakoby funkcja informacyjna nie była funkcją pierwotną czasopisma, za którą uważa się odnotowanie prawa pierwszeństwa do odkryć naukowych. Takie stanowisko nie znajduje jednak potwierdzenia w historii powstania czasopism i zostało słusznie skrytykowane i odrzucone przez Nowaka. Owa funkcja roszczeniowa, zabieganie o palmę pierwszeństwa i związany z tym prestiż w środowisku pojawiły się wyraźnie dopiero na przełomie XVII i XVIII wieku w związku ze słynną „wojną różniczkową" między Izaakiem Newtonem i Gottfriedem Leibnizem. Pierwszy z nich opracował podstawy rachunku różniczkowego i całkowego w 1666 roku, ale opublikował je dopiero w 1693 roku, podczas gdy Leibniz pracował nad tymi samymi zagadnieniami w 1674 roku i wydał swe ustalenia drukiem w roku 1684. Później, w latach 1709-1716, Newton oskarżał go publicznie o wykorzystanie informacji przekazanych mu w prywatnej korespondencji i w rezultacie o plagiat. Problem pierwszeństwa w tym przypadku pozostaje do dzisiaj nierozstrzygnięty,

\footnotetext{
${ }^{12}$ Nie można jednak zapominać, że wcześniej również istniała w nauce europejskiej instytucja recenzji w postaci cenzury prewencyjnej i wpisywania do indeksu tytułów uznanych za niezgodne z przyjętym obrazem rzeczywistości.

${ }^{13}$ P. Nowak, Wybrane problemy efektywności polskich czasopism naukowych z dziedziny humanistyki, Poznań 2000, s. 32-35.
} 
ale ta właśnie wojna stworzyła (albo jedynie ujawniła) nową funkcję czasopism naukowych.

Wracając do pytania o przetrwanie czasopisma naukowego w obecnym kształcie (w tym również w postaci elektronicznej), można stwierdzić, że zależy to od wyczerpania się samej formuły czasopisma, a tym samym od przejęcia jego współczesnych funkcji przez inne narzędzia i procedury w ramach społeczności uczonych. Liczyć się przy tym będą funkcje dominujące, konieczne, a liczne dodatkowe nie będą miały większego znaczenia. Za takie naczelne i podstawowe funkcje powszechnie uznaje się cztery: 1) przekaz informacji, 2) selekcję jakościowa, 3) archiwizowanie informacji, 4) przynoszenie uznania autorom ${ }^{14}$. Nasuwa się zatem pytanie, czy i które $z$ nich mogą być zastąpione przez nowoczesne technologie, a tym samym - w jakim stopniu czasopisma naukowe są jeszcze niezbędne, $\mathrm{w}$ jakim zaś stały się spetryfikowanym rytuałem. $W$ tym celu na niektóre z wymienionych funkcji trzeba będzie spojrzeć od nieco innej strony i zmodyfikować lub uzupełnić ich rozumienie.

Przekaz informacji to raczej ich upowszechnianie czy - jak wola postmoderniści - „rozplenienie” (od angielskiego dissemination). Na owe informacje składają się rezultaty badań, odkryć, ustaleń, przemyśleń, proponowane hipotezy, prognozy i analizy - wszystko, co potocznie uznawane jest za rezultaty działalności naukowej. W ramach tej funkcji można jednak wyróżnić dodatkowo subfunkcje komunikacji, relacji i udostępniania, z których pierwsza zakłada pewną interaktywność (udział przynajmniej dwóch, a zwykle wielu osób), a druga i trzecia są tylko potencjalne (nie musi być odbiorcy informacji, choć jest on pożądany). $W$ tradycyjnym czasopiśmie pierwsza $\mathrm{z}$ tych funkcji realizowana jest przede wszystkim przez polemiki, dyskusje, "dwugłosy” i recenzje, druga przez aktualności z branży, ogłoszenia, relacje z konferencji czy nekrologi, a trzecia przez udostępnianie danych i materiałów, edycji źródłowych, bibliografii czy ikonografii. Funkcja upowszechniania wraz z jej trzema subfunkcjami już od dawna może być (i bywa) realizowana nie za pośrednictwem czasopism naukowych, ale znacznie bardziej efektywnie przez nowoczesne technologie. Publikacja w sieci jest dostępna praktycznie dla wszystkich, a coraz powszechniejsze ostatnio "samopublikowanie” nie stawia żadnych ograniczeń1 ${ }^{15}$. Komunikacja w środowiskach uczonych za pośrednictwem poczty elektronicznej (od 1971 roku), list dyskusyjnych (od 1975 roku) i grup

\footnotetext{
${ }^{14}$ Ibidem, s. 33.

${ }^{15}$ P. Nowak, „Samopublikowanie”... Szczególnie istotny dla rewizji dotychczasowego systemu recenzji okazał się spektakularny casus Sokala. Zob. A. Sokal, J. Bricmont, Modne bzdury. O nadużyciach nauki popetnianych przez postmodernistycznych intelektualistów, przeł. P. Amsterdamski, Warszawa 2004.
} 
dyskusyjnych Usenet (od 1979 roku) wykształciła już nie tylko nowoczesne fora dla debat naukowych, ale też całą socjologiczną otoczkę w postaci nowych reguł właściwego zachowania i rytuałów związanych z udziałem $\mathrm{w}$ takich dyskusjach. Z kolei udostępnianie materiałów i artykułów jest praktykowane (jeżeli tylko autor lub wydawca nie są $w$ tym względzie ograniczeni obowiązującym prawem) dzięki technologiom FTP (od 1973 roku) i przede wszystkim WWW/HTML (od 1992 roku). Istniejący od 1993 roku format plików PDF zapewnia wierność oryginałowi i jest powszechnie stosowany w środowiskach naukowych, zwłaszcza po uwolnieniu go przez firmę Adobe. Można zatem powtórzyć za Michaelem Clarke'em, że "gdyby upowszechnianie było jedyną funkcją czasopism naukowych, czasopisma już by dawno zniknęły"16.

Powszechny dostęp do „samopublikowania” w Internecie nie pozwala jednak na wypełnianie drugiej z podstawowych funkcji, a mianowicie selekcji jakościowej. Jeżeli każdy może publikować, co chce, to nie ma możliwości oddzielenia wartościowych artykułów od niewiele wartych ani ich gradacji. Często słyszy się opinie, że „Internet to wielki śmietnik” $\mathrm{i}$ jest $\mathrm{w}$ nich sporo prawdy właśnie $\mathrm{z}$ tego względu. W czasopismach taka wstępna weryfikacja i kontrola jakości odbywa się przez wspomniane wyżej recenzowanie prewencyjne peer-review. Choć podejście to jest $\mathrm{w}$ ostatnich latach szeroko krytykowane ${ }^{17}$, inne propozycje nie znalazły jeszcze powszechnego uznania. Działają co prawda repozytoria publikacji cyfrowych powiązane z recenzowaniem jako warunkiem zamieszczenia tam artykułu, ale taki układ staje się praktycznie czasopismem elektronicznym, musi bowiem istnieć redakcja pośrednicząca między autorem i recenzentem. Większość czasopism naukowych wydawanych wyłącznie w formie elektronicznej działa na takiej właśnie zasadzie. Pewne możliwości otwiera w tym względzie również „samopublikowanie", jeżeli do artykułu dołączona będzie recenzja uzyskana przez autora bezpośrednio od autorytetu w danej dziedzinie (choć wówczas zawsze pozostaje kwestia jej wiarygodności, zwłaszcza w wąskich kręgach specjalistów) albo jeżeli publikacja będzie „wisiała” i oczekiwała na recenzje po publikacji. Takie i podobne eksperymenty nie rokują jednak rychłego odejścia od dotychczasowego systemu recenzji, dokonywanej nawet tylko w samej redakcji, a tym samym od tradycyjnego formatu czasopisma.

Niezwykle ważna, a często niedoceniana, jest funkcja archiwizowania informacji, czyli zachowywania dorobku nauki dla przyszłych pokoleń.

\footnotetext{
${ }^{16}$ M. Clarke, op.cit.

${ }^{17}$ P. Nowak, „Samopublikowanie”..., s. 96-97.
} 
Na bieżąco jest ona istotna w zakresie nadawania publikacjom „odsyłaczy" (w postaci tytułu czasopisma, rocznika, numeru i stron), do których mogą się odwoływać inni autorzy. W świecie elektronicznym nie jest to oczywiście żadna trudność, każda publikacja w Internecie ma bowiem z konieczności swój unikatowy adres URL. Kiedy jednak wydawca (właściciel serwera) zbankrutuje albo z innych względów przestanie utrzymywać dotychczasowe zasoby, taki adres staje się nieaktualny, a sam artykuł niedostępny. Co ważniejsze jednak, publikacja wyłącznie elektroniczna w żadnym stopniu nie gwarantuje prawdziwej długowieczności i przetrwania artykułów czy innych danych ${ }^{18}$. Nikt nie jest w stanie przewidzieć, jakie technologie, jaki sprzęt, nośniki danych czy formaty ich zapisu będą w powszechnym użyciu za 20 lat, a o tym, co będzie za lat 200, trudno nawet fantazjować. Tymczasem dla zachowania dorobku kulturowego i dla przyszłych historyków są to bardzo krótkie okresy. Dzisiaj odnajduje się dokumenty sprzed kilku tysięcy lat, zapisane na glinianych tabliczkach lub papirusach, które nie tylko przetrwały fizycznie jako artefakty, ale też są nadal czytelne. Nawet jeżeli nie daje się od razu zrozumieć ich pisma czy języka, można je analizować i interpretować. Współczesne nośniki danych (płyty CD, twarde dyski, pendrive'y) już po kilku albo kilkunastu latach ulegają trwałemu uszkodzeniu, a ich zawartość przestaje być czytelna. A gdyby nawet założyć powstanie w niedługiej przyszłości bardzo trwałych nośników, to zarówno sprzęt, jak i formaty zapisu (programy do odczytu) danych z całą pewnością nie będą dostęp$n \mathrm{e}^{19}$. Tak więc publikacje drukowane $\mathrm{w}$ wielu egzemplarzach na papierze (najlepiej dobrej jakości) i przechowywane w wielu bibliotekach jednocześnie nadal stanowią jedyny pewny sposób na przetrwanie informacji, a format czasopisma pozwala na łatwy dostęp.

Czwarta wreszcie z najważniejszych funkcji czasopisma naukowego - przynoszenie uznania autorom - może być rozpatrywana również w kilku aspektach. Wspomniana już wyżej kwestia odnotowania pierwszeństwa autora odkrycia, wynalazku czy teorii nie zawsze jest prosto przekładalna na publikacje elektroniczne. $\mathrm{W}$ wielu dziedzinach istnieją jeszcze zapisy o konieczności wydania drukiem, czego przykładem może być odmowa rejestracji taksonów opublikowanych w latach 2008-2009

\footnotetext{
${ }^{18}$ R.T. Prinke, "Kwaśne pliki”. Standardy dygitalizacji i problem dtugowieczności zasobów cyfrowych, w: Dygitalizacja zbiorów bibliotecznych, red. E. Stefańczyk, Warszawa 2006, s. 60-65.

${ }^{19}$ Kilkanaście lat temu bardzo popularne były w Polsce edytory tekstu ChiWriter i TAG. Dzisiaj odczytanie stworzonych za ich pomocą plików jest prawie niemożliwe. Podobnie odczytanie czegokolwiek z dyskietek 5 1/4 cala wymaga praktycznie niedostępnych już nigdzie stacji dyskietek.
} 
w elektronicznym czasopiśmie recenzowanym PloS ONE ${ }^{20}$. Obok jednak tej funkcji rejestracyjno-kronikarskiej duże znaczenie ma obecnie uznanie ze strony pracodawców i instytucji udzielających grantów, które wynika z oceny parametrycznej czasopisma (impact factor i liczba cytacji) oraz jego prestiżu $w$ ramach konkretnej specjalności ${ }^{21}$. System ten również podlega $w$ ostatnich latach ostrej krytyce, a wiele znaczących instytucji finansujących badania naukowe na świecie przestało brać pod uwagę tytuły czasopism (czyli impact factor), w których publikował wnioskujący o przyznanie grantu, na korzyść niezależnej oceny jego rzeczywistego dorobku (merytorycznej zawartości artykułów bądź książek) ${ }^{22}$. Można zatem oczekiwać oderwania oceny publikacji naukowej od konkretnego czasopisma, w którym się pojawiła, a tym samym pozbawienia czasopism tej funkcji.

Obok omówionej wyżej funkcji selekcji jakościowej czasopismo naukowe dokonuje też selekcji tematycznej, ułatwiając tym samym uczonemu dotarcie do interesujących go publikacji, bez konieczności przeglądania wszystkich czasopism recenzowanych. Są zatem czasopisma przeglądowe dla całej dyscypliny i periodyki dla wąskich specjalności. Przykładowo, każdy polski historyk zapewne zaznajomi się z zawartością „Kwartalnika Historycznego", ale tylko niektórzy historycy będą regularnie sięgali po „Kwartalnik Historii Nauki i Techniki”, ,"Dzieje Najnowsze” czy „Przeszłość Demograficzną Polski”. Taka wstępna segregacja jest oczywiście równie łatwa w świecie cyfrowym. Co więcej, można jej dokonywać w wielu wymiarach, a więc jeden artykuł może się pojawiać równocześnie w wielu obszarach tematycznych, jeżeli dotyczy różnych tematów, bądź też ma charakter interdyscyplinarny.

Nowożytna metoda naukowa, której integralnym elementem stało się czasopismo naukowe, jest jednym z mitów nauki ${ }^{23}$. Jej precyzyjne zdefiniowanie okazało się niemożliwe mimo czterech wieków starań filozofów i teoretyków nauki, a Paul Feyerabend wykazał wiele jej niespójności. Jedna z fundamentalnych idei owego mitu zakłada powszechny dostęp do osiągnięć nauki i swobodę ich wykorzystywania. Początek epoki sieci komputerowych, a potem Internetu, zrodził wśród wielu uczonych nadzieję na realizację tego aspektu mitu, ale postępująca komercjalizacja dostępu do zasobów naukowych pokazała, że dysproporcje w dostępie

${ }^{20}$ PLoS ONE, http://www.plosone.org [dostęp: 20.02.2010].

${ }^{21}$ P. Nowak, Wybrane problemy...

${ }^{22}$ W 2010 roku były to m.in. National Science Foundation (USA), Research Assessment Exercise (Wielka Brytania), Deutsche Forschungsgemeinschaft (Niemcy).

${ }^{23}$ J. Jeszke, Mity polskiej historiografii nauki, Warszawa 2007. 
rosna, a nie maleją ${ }^{24}$. Podczas gdy w krajach wysoko rozwiniętych, z dużymi nakładami na naukę, większość bibliotek stać na opłacanie licencji, pozostałe obszary są wyłączone z tej nowej respublica literaria. Co więcej, w sytuacji kryzysu i związanej z nim redukcji liczby tytułów czasopism naukowych prenumerowanych $\mathrm{w}$ formie papierowej, rozziew między owymi obszarami jeszcze bardziej się powiększa ${ }^{25}$.

Można zatem stwierdzić, że chociaż część z najważniejszych funkcji czasopism naukowych można już dzisiaj zastąpić innymi narzędziami, dostępnymi dzięki rozwojowi technologii informatycznych, pozostają problemy weryfikacji jakości (recenzji), a także zapewnienia długowieczności danych w rozumieniu archiwalnym. Podczas gdy pierwszy z tych problemów ma naturę formalną i zapewne pojawią się nowe rozwiązania, niezależne od tradycyjnej formuły czasopisma, drugi związany jest z fizycznym przetrwaniem, jakie obecnie zapewnić może jedynie druk na papierze i rozproszenie egzemplarzy. Jak można się jednak spodziewać, rozwój technologiczny przyniesie i w tym względzie, choć pewnie nieprędko, nowe możliwości. Wówczas dopiero można będzie rozsądnie dyskutować o zamknięciu ery czasopism i migracji do nowych procedur w działalności naukowej.

Nawet możliwości technologiczne i formalne nie spowodują jednak, że znacząca większość naukowców szybko zgodzi się na inne rozwiązania. Czasopismo nie jest bowiem tylko narzędziem nauki, ale przede wszystkim rytuałem odprawianym przez uczonych, a ten nie jest podatny na zmiany nawet w obliczu oczywistych argumentów logicznych. Jak każdy rytuał, instytucja czasopisma naukowego tworzy i utrwala tożsamość jego uczestników, w tym przypadku tożsamość społeczności uczonych w ramach subkultur intelektualnych. Są to zapewne najgłębiej zakorzenione, często nieuświadamiane przekonania - istotnie „artykuły wiary”, jak sugerował przytaczany wcześniej Bruce Morton.

\footnotetext{
${ }^{24}$ Dostęp do takich baz, jak Project Muse, JSTOR, Early English Books Online itd., mają dopiero od 2-3 lat tylko bardzo nieliczne biblioteki w Polsce, i to nie w pełnym zakresie.

${ }^{25}$ Wystarczy sprawdzić w Centralnym Katalogu Czasopism Zagranicznych Biblioteki Narodowej (http://mak.bn.org.pl), jak w ciągu ostatnich dwudziestu lat regularnie zmniejszała się liczba bibliotek kupujących dowolny tytuł.
} 


\title{
RAFAŁ T. PRINKE \\ Traditional functions of scholarly journals and modern communication technologies
}

\begin{abstract}
Since mid-17th century, the scholarly journal was the most important medium of communication within the community of scholars. It also has a number of other functions, such as quality control, archiving, and recognition of authors. The necessity of journals for the development of science and scholarship has been questioned, also from the perspective of cultural anthropology. Some of its functions can already be replaced with other solutions, made available by new information and communication technologies. A number of proposals for a new formula of the journal do not, however, ensure proper fulfilment of all its traditional functions. It seems both important and interesting to look at the scholarly procedures related to publishing in journals as a ritual strengthening self-identification and integration of a scholarly subcommunity related to a particular research area and methodological school.
\end{abstract}

KeY wORDs: scholarly journals, electronic journals, functions of journals, ritual behaviour in scholarship. 
